\title{
AN EVALUATION OF THE NEW ZEALAND CODE TORSIONAL PROVISION
}

\author{
W. K. Tso', C. M. Wong'
}

\begin{abstract}
SUMMARY
This study evaluates the New Zealand torsional provision in the 1984 and 1992 editions of the New Zealand loading code (NZS 4203) based on the inelastic responses of a single mass model having lateral load resisting elements in two orthogonal directions and subjected to bidirectional base excitations. It is shown that for systems having torsional stiffnesses that exceed a minimum value, the provision in NZS 4203:1984 will restrict the ductility demands on the resisting elements no more than those of a similar but torsionally balanced system. This minimum torsional stiffness depends on the structural eccentricity of the system. For systems with torsional stiffness less than the minimum, the stiff edge elements can experience additional ductility demand because the 1984 edition of the Code permits excessive strength reduction on the stiff edge elements. In the 1992 edition, the Code imposes a minimum torsional stiffness of a structure in the form of edge displacement ratios. With this new requirement, the danger of additional ductility demand on the stiff edge element is eliminated. Therefore, the torsional provision in the current edition will ensure no additional ductility demands on all lateral force elements caused by torsion.
\end{abstract}

\section{INTRODUCTION}

A number of buildings that suffered heavy damage in Mexico City in the 1985 Michanocan earthquake can be attributed to excessive torsional responses during the earthquake [1]. Such observation gives rise to the current interest to evaluate the adequacy of torsional provisions in different codes [2-6].

One key purpose of torsional provision is to limit the additional ductility experienced by the lateral load resisting elements induced by torsional motions. Theoretical studies [3] on the seismic responses of torsionally unbalanced systems showed that elements at the flexible edge of the systems will experience additional displacements, when compared to those of a similar but torsionally balanced system. To limit additional ductility demands, one needs to provide extra strength to these elements. Elements at the stiff edge of a torsionally unbalanced system may, or may not experience reduction of displacements depending on the torsional stiffness of the system. To limit additional ductility demands on these elements, one should not reduce the strength of these elements excessively.

In this paper, an evaluation is carried out of the torsional provision in both the 1984 and 1992 editions of the New Zealand code [NZS 1984]. The study focuses on the importance of the torsional stiffness of the system on the strength distribution and in turn its effect on the additional ductility demand on the elements in the system. It is shown that the New Zealand torsional provision in the 1984 edition of the New Zealand code can limit the ductility demand of

Dept. of Civil Engineering and Engineering Mechanics, McMaster University, Hamilton, Ontario, Canada L8S $4 L 7$ all structural elements to no more than those in a similar but torsionally balanced system if the torsional stiffness of the system exceeds a minimum value. This minimum value is a function of eccentricity. For systems with torsional stiffness less than the minimum value, the ductility demands on the stiff edge elements can be substantially larger than those of the torsionally balanced systems because the code allows excessive reduction strength to the stiff edge elements. By imposing a limit on the minimum torsional stiffness of structures in the form of edge displacement ratios, the current edition [NZS 4203:1992] of the Code eliminates the danger of additional ductility demands on the stiff edge elements and ensures that there will be no additional ductility demands on all lateral force resisting elements due to torsion.

\section{STRUCTURAL MODEL}

The structural model used in the study consists of a rigid rectangular slab supported by six lateral load resisting elements. The slab has a plan dimension of $\mathrm{a}$ by $\mathrm{b}$ and $\mathrm{a}$ mass $\mathrm{M}$. The six lateral load resisting elements are arranged as shown in Figure 1. Elements 1 and 2 and 3 (referred to as Y-direction elements hereafter) are parallel to the y-axis. The out-of-plane stiffness and strength of the elements are assumed negligible; therefore, they provide lateral stiffness and strength in the Y-direction only. Similarly elements 4, 5 , and 6 (referred to as $\mathrm{X}$ direction elements hereafter) provide lateral stiffness and strength in the X-direction only.

The initial in-plane stiffness and yield strength of the $Y$-direction elements are denoted by $\mathrm{k}_{\mathrm{yi}}$ and $\mathrm{f}_{\mathrm{yi}}(\mathrm{i}=1,2,3)$, and for X-direction elements, $\mathrm{k}_{\mathrm{xj}}$ and $\mathrm{f}_{\mathrm{xj}},(\mathrm{j}=4,5$ and 6$)$. All elements are assumed to have bilinear hysteretic 


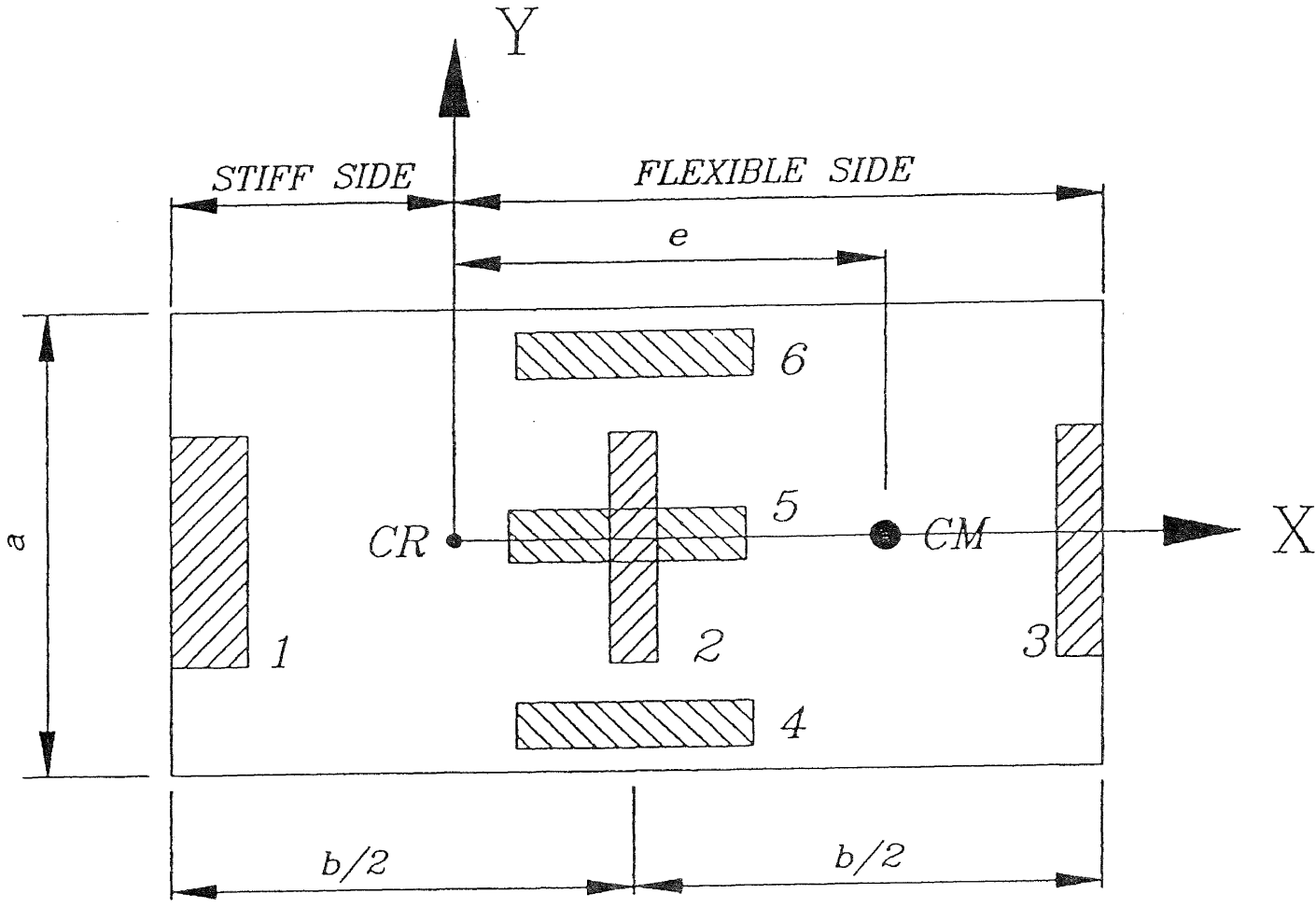

Figure 1 Torsionally unbalanced single mass system.

force-deformation characteristics with the secondary stiffness equal to 3 per cent of their respective initial elastic stiffnesses. The locations of the Y-direction elements on the slab are fixed where elements 1 and 3 are at the left and the right edge of the slab respectively, and element 2 is at the centre of the slab. For the X-direction elements, element 5 is fixed at the centre of the slab and elements 4 and 6 are at equal distance from the opposite sides of element 5 . In the present study, the type of torsionally unbalanced system considered will be restricted to cases where elements 4 and 6 are identical so that eccentricity occurs in the X-direction and such eccentricity will affect the design of the Y-direction elements only.

\section{STIFFNESS DISTRIBUTION}

The total lateral stiffnesses in the X-and Y-directions are denoted by $K_{x}$ and $K_{y}$ respectively. In this study, it is assumed that $\mathrm{K}_{\mathrm{x}}=\mathrm{K}_{\mathrm{y}}$. The stiffness of the X-direction elements 4, 5 and 6 are symmetrically distributed such that $\mathrm{k}_{\mathrm{x} 4}=\mathrm{k}_{\mathrm{x} 6}$. The stiffness of the elements 1,2 and 3 are distributed such that the centre of rigidity (CR) is located at a distance $\eta(\geq 0)$ to the left of element 2 . CR is taken as the origin of the coordinate system. When $\eta=0$, the system will have its $C R$ centrally located with respect to the slab.

The torsional stiffness of the system is equal to the second moment of stiffness. The contribution to the torsional stiffness from the $\mathrm{X}$-direction elements and $\mathrm{Y}$-direction elements will be denoted by $\mathrm{K}_{\theta \mathrm{x}}$, and $\mathrm{K}_{\theta \mathrm{y}}$ respectively; and the total torsional stiffness $\mathrm{K}_{\theta}=\mathrm{K}_{\theta \mathrm{x}}+\mathrm{K}_{\theta \mathrm{y}}$. In the present study, the torsional stiffness of the system is represented by $\rho_{k}$, a normalized radius of gyration defined as

$$
\rho_{k}=\frac{1}{b} \sqrt{\frac{K_{\theta}}{K_{y}}}=\sqrt{\frac{\sum_{i=1}^{3} k_{y i} x_{i}^{2}+\sum_{j=4}^{6} k_{x j} y_{j}^{2}}{\sum_{i=1}^{3} k_{y i}}}
$$

where $x_{i}=$ the $x$ coordinate of element $i(i=1,2,3), y_{j}=$ the y coordinate of element $j(j=4,5,6)$, normalized to $b$. A dimensionless parameter $\lambda$ is introduced to denote the fraction of torsional stiffness contributed by the $\mathrm{X}$-direction elements. It is defined as

$$
\lambda=\frac{\mathrm{K}_{\theta \mathrm{x}}}{\mathrm{K}_{\theta}}
$$

$\lambda=0$ implies that the total torsional stiffness is contributed entirely by elements 1,2 and 3 , a case already considered by Tso and Zhu (1992).

\section{MASS DISTRIBUTION}

The total mass of the system $M$ is such that the uncoupled lateral periods in both the $\mathrm{X}$ and $\mathrm{Y}$ direction are equal to $0.5 \mathrm{~s}$. Part of the total mass is uniformly distributed over the entire slab and the remaining mass is uniformly distributed along the right edge line. The relationship between the two parts of the total mass depends on the location of $\mathrm{CM}$ as specified by a given eccentricity. Using such mass distribution the mass polar moment of inertia can be computed after the aspect ratio of the slab $a / b$ is specified. 
In this study, $\mathrm{a} / \mathrm{b}$ is taken as 0.5 . The mass distribution adopted herein is the same as that used by Tso and Zhu (1992).

When the mass distribution is such that $\mathrm{CM}$ coincides with $\mathrm{CR}$, the model becomes torsionally balanced and is used as the reference system. The strength distribution and responses of such a reference model are used for normalization to highlight the torsional effect on the associated torsionally unbalanced models.

\section{STRENGTH DISTRIBUTION}

The nominal lateral design force in the $\mathrm{X}$ and $\mathrm{Y}$ directions are $\mathrm{F}_{\mathrm{x}}$ and $\mathrm{F}_{\mathrm{y}}$. They are related to the design spectral acceleration $\mathrm{a}^{*}$ by

$$
\mathrm{F}_{\mathrm{x}}=\frac{\mathrm{Ma}^{*}}{\mathrm{R}_{\mathrm{x}}}, \mathrm{F}_{\mathrm{y}}=\frac{\mathrm{Ma}^{*}}{\mathrm{R}_{\mathrm{y}}}
$$

$\mathrm{a}^{*}$ is taken from the 5 percent damped acceleration spectrum of Newmark and Hall (1982) normalized to a peak ground acceleration of $0.2 \mathrm{~g}$. The strength reduction factors $R_{x}$ and $R_{y}$ are taken to be 5 so that all elements will be excited well into the inelastic range when subjected to the bidirectional ground excitations.

Since $\mathrm{X}$ is an axis of symmetry, the strengths of the $X$-direction elements $f_{x j}(j=4,5,6)$ can be evaluated as proportional to their relative stiffnesses. Additional strength is assigned to $f_{x 4}$ and $f_{x 6}$ to allow for the accidental torsion effect as specified by the design code.

The lateral strength for the Y-direction elements are obtained from the nominal design force $\mathrm{F}_{\mathrm{y}}$ based on static equilibrium consideration and they can be expressed as

$$
f_{y i}=f_{y i}^{0}\left(1-\frac{e_{d} x_{i}}{\rho_{k}^{2}}\right) \equiv f_{y i}^{0} \Gamma_{i}
$$

where $\mathrm{f}_{\mathrm{yi}}{ }^{0}$ is the element strength if no torsional provision is taken into account in designing the torsionally unbalanced system. Therefore, the change of design strength of any element due to torsional provision requirement is represented by the element strength ratio $\Gamma_{\mathrm{i}}$.

In the New Zealand code, the torsional provision can be stated in terms of a pair of design eccentricities

$$
\begin{aligned}
& \left(e_{d}\right)_{a}=e+0.1 \\
& \left(e_{d}\right)_{a}=e-0.1
\end{aligned}
$$

in which $\mathrm{e}_{\mathrm{d}}$ and $\mathrm{e}$ are the design eccentricity and the eccentricity of the system normalized to $b$. The design strength of the element $f_{y i}$ is based on either Equations 5a or $5 b$, which ever causes the larger load demand. Using design eccentricities in the form given in equation 5 , the strength ratio for element 3 on the flexible side of the system can be expressed as

$$
\left(\Gamma_{3}\right)_{\mathbf{a}}=1+\frac{\mathbb{X}_{3}}{\rho_{\mathbf{k}}^{2}}(e+0.1)
$$

$$
\left(\Gamma_{3}\right)_{b}=1+\frac{x_{3}}{\rho_{k}^{2}}(e-0.1)
$$

Since $\left(\Gamma_{3}\right)_{a}>\left(\Gamma_{3}\right)_{b}$, the design strength of element 3 on the flexible side is always governed by $\left(\Gamma_{3}\right)_{a}$.

The strength ratio for element 1 located on the stiff side of the system $\left(\mathrm{x}_{1}<0\right)$, can be written as

$$
\begin{aligned}
& \left(\Gamma_{1}\right)_{a}=1-\frac{\left|\mathrm{x}_{1}\right|}{\rho_{\mathrm{k}}^{2}}(\mathrm{e}+0.1) \\
& \left(\Gamma_{1}\right)_{\mathrm{b}}=1-\frac{\left|\mathrm{x}_{1}\right|}{\rho_{\mathrm{k}}^{2}}(\mathrm{e}-0.1)
\end{aligned}
$$

The design strength of this element can be governed by either $\left(\Gamma_{1}\right)_{\mathrm{a}}$ or $\left(\Gamma_{1}\right)_{\mathrm{b}}$, depending on the torsional stiffness and eccentricity of the system. For systems with small eccentricity such that $\mathrm{e}<0.1,\left(\Gamma_{1}\right)_{\mathrm{b}}$ is larger than unity. Therefore, the design strength of element 1 will be given by $\left(\Gamma_{1}\right)_{\mathrm{b}}$ and is not reduced, irrespective of $\rho_{\mathrm{k}}$.

For systems having large eccentricity such that $e>0.1$, both $\left(\Gamma_{1}\right)_{a}$ and $\left(\Gamma_{1}\right)_{b}$ can be positive or negative depending on the torsional stiffness of the system. The design strength of element 1 is then based on the larger of the absolute values of $\left(\Gamma_{1}\right)_{a}$ or $\left(\Gamma_{1}\right)_{b}$. For torsionally flexible systems (small $\rho_{k}$ ), both $\left(\Gamma_{1}\right)_{\mathrm{a}}$ and $\left(\Gamma_{1}\right)_{\mathrm{b}}$ are negative, but $\left|\left(\Gamma_{1}\right)_{\mathrm{a}}\right|>\left|\left(\Gamma_{1}\right)_{\mathrm{b}}\right|$. Therefore, the design strength is based on $\left|\left(\Gamma_{1}\right)_{\mathrm{a}}\right|$. For torsionally stiff systems (large $\left.\rho_{\mathrm{k}}\right),\left(\eta_{1}\right)_{\mathrm{b}}>\left(\eta_{1}\right)_{\mathrm{a}}>0$ and the element strength is given by $\left(\Gamma_{1}\right)_{b}$.

The variation of the strength ratio for element 1 as a function of $\rho_{\mathrm{k}}$ for a system having large eccentricity is schematically shown in Figure 2. The design strength for element 1 is governed by either $\left|\left(\Gamma_{1}\right)_{\mathrm{a}}\right|$ or by $\left(\Gamma_{1}\right)_{\mathrm{b}}$. The intersection of these two curves represents the situation that the design strength is a minimum. The minimum strength ratio is given by

$$
\Gamma_{\min }=\frac{0.1}{\mathrm{e}}
$$

The torsional stiffness which leads to $\mathrm{r}_{\min }$ is designated as $\rho_{\mathrm{k}, \mathrm{cr}}$ and is given by

$$
\rho_{k, c r}=\sqrt{\left|x_{1}\right| e}
$$

Shown in Figures $3 \mathrm{a}$ and $\mathrm{b}$ are the strength ratios for the element on the flexible edge (element 3 ) and the element on the stiff edge (element 1) for different eccentricities and for a structural configuration where CR is centrally located (i.e. $\eta=0)$. The increase in strength in element 3 depends on $\mathrm{e}$ and $\rho_{\mathrm{k}}$. For torsionally flexible systems ( $\rho_{\mathrm{k}}$ small), the strength increase is very rapid. The strength ratio curves for element 1 can be divided into two groups. For small eccentricities ( $\mathrm{e} \leq 0.1$ ), it is always larger than or equal to unity, implying there will be no reduction of strength on element 1. For large eccentricities (e $>0.1$ ), the curves exhibit minimums or troughs. Each trough occurs at $\rho_{k, c r}$ and has a value of $\Gamma_{\min }$ as given in equations 8 and 9 . The larger the value of e, the lower is the minimum and this minimum occurs at a higher values of $\rho_{k}$. To avoid excessive strength reduction of element 1 , one should adjust 


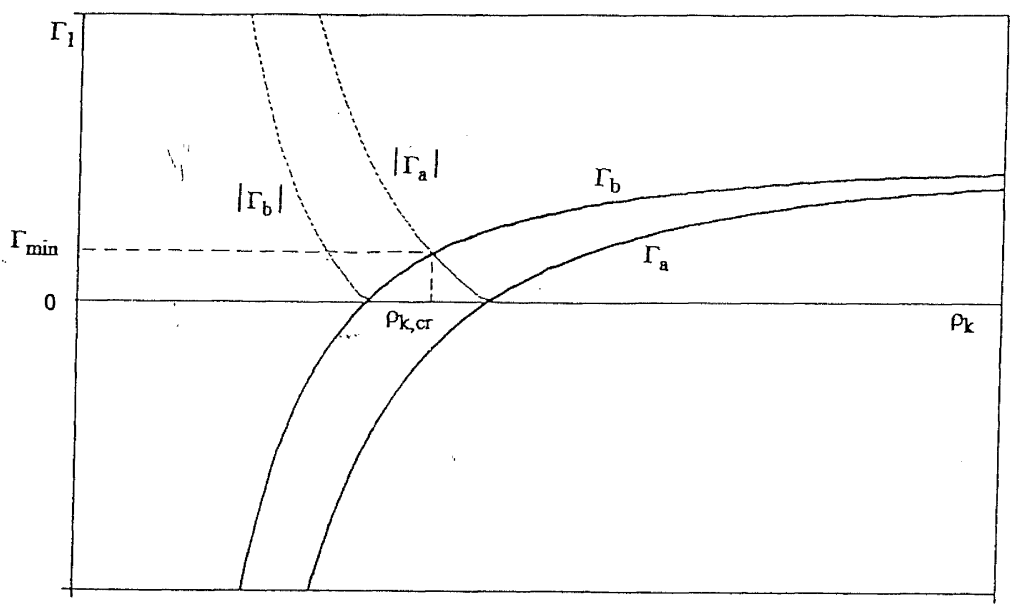

Figure 2 Design strength for stiff edge element.



(a)

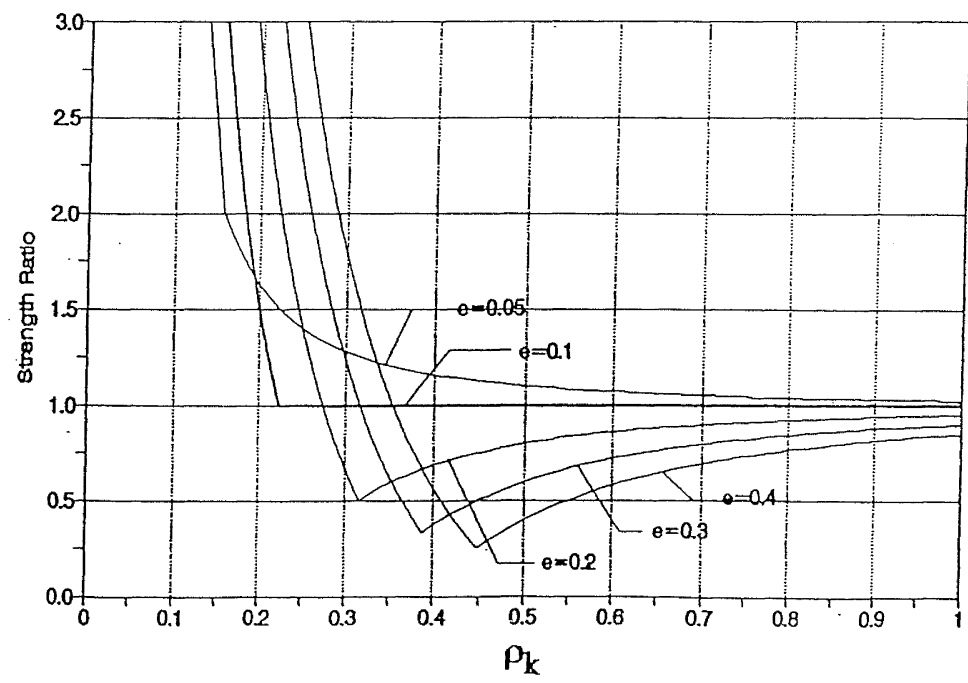

(b)

Figure $3 \quad$ Strength ratio for edge elements, (a) flexible edge element 3; (b) stiff edge element 1;: 


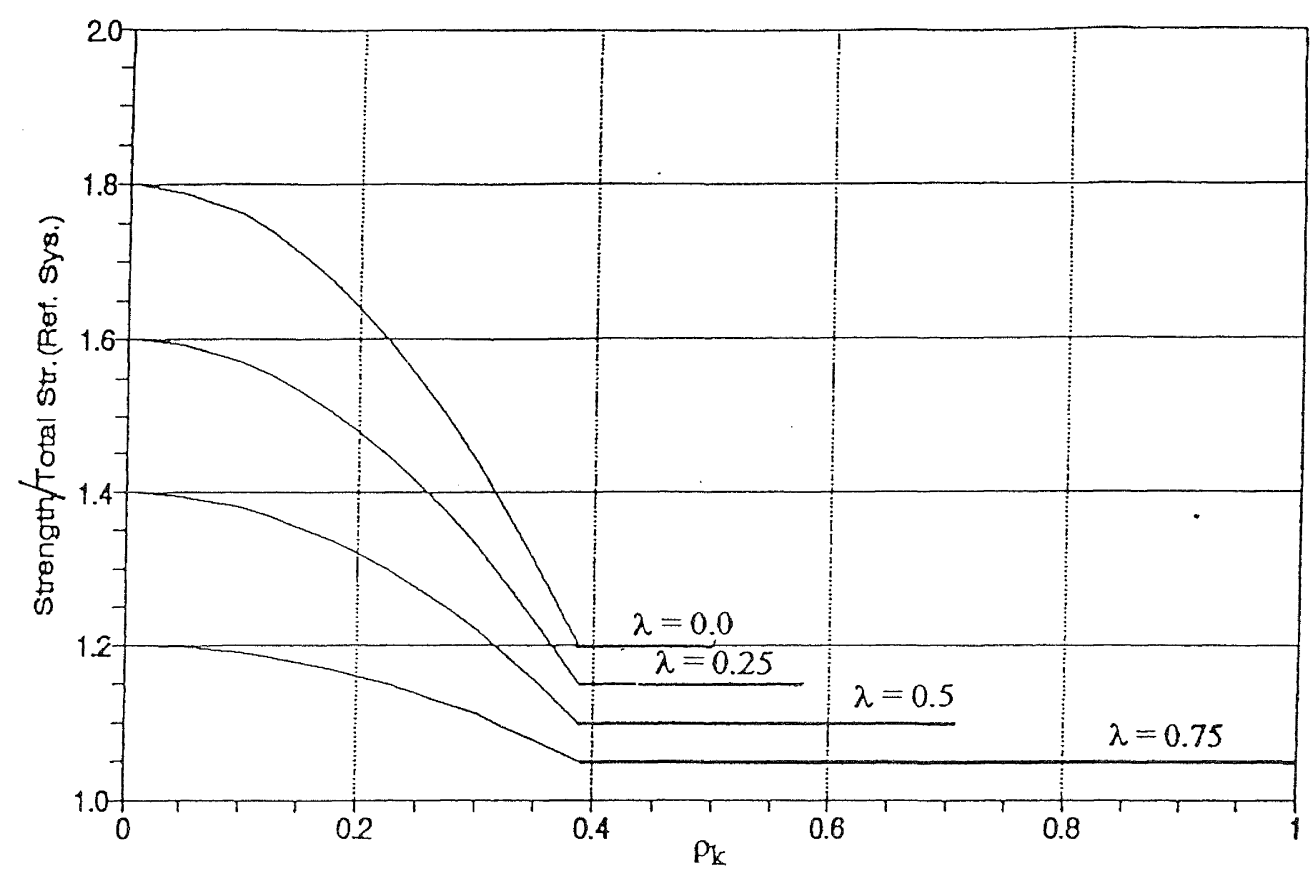

Figure 4 Total strength ratio for the torsionally unbalanced system with $e=0.3$.

the torsional stiffness of the system away from the $\rho_{\mathrm{k}, \mathrm{cr}}$ value by either decreasing or increasing the torsional stiffness of the system. As shown in Figures $3 a$ and $b$, decreasing $\rho_{k}$ from $\rho_{k, c r}$ will lead to a very large increase of element strength for both element 1 and element 3 . A more viable strategy is to increase the torsional stiffness beyond $\rho_{\mathrm{k}, \mathrm{cr}}$. This leads to an increase of strength in element 1 . However, the increase is compensated by the corresponding decrease of strength in element 3 . In the structural configuration considered where CR is centrally located (i.e. $\eta=0$ ), the increase and decrease exactly cancel each other out.

Figure 4 shows a plot of the total strength of the torsionally unbalanced system for an eccentricity $\mathrm{e}=0.3$ normalized by the total strength of the corresponding torsionally balanced reference system. Four values of $\lambda(0,0.25,0.5$ and 0.75$)$ are considered to cover a wide range of torsional stiffness contribution from the X-direction elements. There is a physical limitation on the maximum value of $\rho_{\mathrm{k}}$ associated with each $\lambda$ value which explains that some curves do not cover the whole range of $\rho_{\mathrm{k}}$ in the figure. The penalty on the Y-direction strength for having little contribution to torsional stiffness from elements in the X-direction is evident. For a given $\lambda$, substantial increase in overall strength is required when $\rho_{\mathrm{k}}$ is less than $\rho_{\mathrm{k}, \mathrm{cr}}(=0.39)$. However, the total strength remains constant when $\rho_{k}$ exceeds $\rho_{k, c r}$. The extent by which $\rho_{k}$ needs to be increased beyond $\rho_{k, c r}$ to avoid the problem of low design strength can be addressed only after one evaluates the inelastic seismic responses of the systems.

\section{INPUT GROUND MOTIONS}

An ensemble of 10 pairs of strong motion records are used as input ground motions. Their selection was based on the criterion that the shapes of their acceleration response spectra are similar to the shape of the design spectrum. This choice is to minimize the effects of mismatch in frequency content between the input ground motions and the design spectrum. For each pair of records, the record that has the higher peak acceleration is taken as the input in the Y-direction. The Y-direction records are normalized to a peak ground acceleration of $0.2 \mathrm{~g}$, consistent with peak acceleration assumed in the design. Each $\mathrm{X}$-direction record is modified by the same factor that applies to the corresponding Y-direction record. The mean of the 5\% damped acceleration response spectrum for the ensemble of records is shown in Figure 5. Shown in the same figure is the Newmark-Hall spectrum used for the design of the structural models. Pertinent information on these 10 pairs of earthquake records is given in Table 1.

\section{INELASTIC RESPONSES}

Once the properties of a torsionally unbalanced system and the input ground motions for the system are specified, the equations of motion can be solved numerically. The Newmark-beta method with beta equal to $1 / 6$ is used. The damping matrix is expressed as a linear combination of the mass and the initial stiffness matrix. The combination coefficients are selected to give $5 \%$ of critical damping in the first two vibrational modes.

The structural configurations investigated consist of plans with CR centrally located (i.e. $\eta=0$ ), and $\lambda$ takes on the values $0,0.25,0.50$ and 0.75 . Four eccentricity values, $\mathrm{e}=$ $0.1,0.2,0.3$ and 0.4 are used in the computation to cover systems with small to very large eccentricities.

The parameters of interest are the maximum displacements and ductilities of the resisting elements at the flexible edge and the stiff edge of the structure. To quantify the effect of torsional response, each of these parameters is normalized with its counterpart computed for the reference torsionally 
5\% Damped Average Spectrum

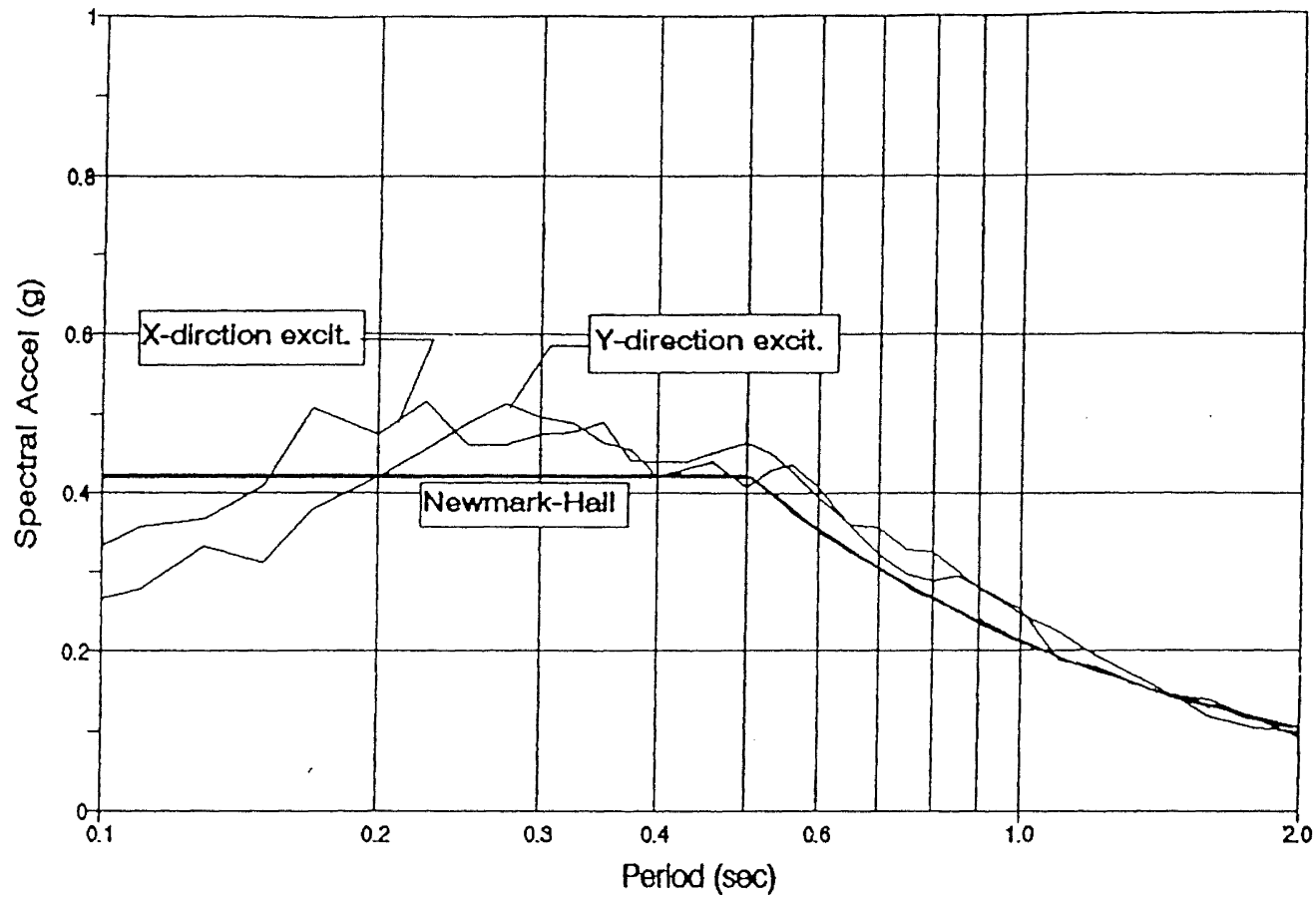

Figure $5 \quad$ Mean 5\% damped $X$ and $Y$ direction input spectra.

Table 1. List of Input Ground Motions

\begin{tabular}{|c|c|c|c|c|c|c|c|c|}
\hline Earthquake & Date & Mag. & Site & $\begin{array}{c}\text { Soil } \\
\text { Condition }\end{array}$ & $\begin{array}{l}\text { Source } \\
\text { Dist. } \\
(\mathrm{km})\end{array}$ & $\begin{array}{l}\text { Comp. } \\
\text { Dir. }\end{array}$ & $\begin{array}{l}\text { Max. } \\
\text { Acc. (A) } \\
\text { (g) }\end{array}$ & $\begin{array}{c}\text { Input } \\
\text { Direction }\end{array}$ \\
\hline $\begin{array}{l}\text { Imperial Valley, } \\
\text { California }\end{array}$ & $05 / 18 / 40$ & 6.6 & El Centro & $\begin{array}{l}\text { Stiff } \\
\text { Soil }\end{array}$ & 8 & $\begin{array}{l}\text { S00E } \\
\text { S90W }\end{array}$ & $\begin{array}{l}0.348 \\
0.214\end{array}$ & $\begin{array}{l}\mathrm{Y} \\
\mathrm{X}\end{array}$ \\
\hline $\begin{array}{l}\text { Kern County, } \\
\text { California }\end{array}$ & $07 / 21 / 52$ & 7.6 & Taft Lincoln School Tunnel & Rock & 56 & $\begin{array}{l}\mathrm{S} 69 \mathrm{E} \\
\mathrm{N} 21 \mathrm{E}\end{array}$ & $\begin{array}{l}0.179 \\
0.156 \\
\end{array}$ & $\begin{array}{l}\mathrm{Y} \\
\mathrm{X}\end{array}$ \\
\hline $\begin{array}{l}\text { San Fernando, } \\
\text { California }\end{array}$ & $02 / 09 / 71$ & 6.6 & $\begin{array}{l}\text { Hollywood Storage P.E. } \\
\text { Lot, LA }\end{array}$ & $\begin{array}{l}\text { Stiff } \\
\text { Soil }\end{array}$ & 35 & $\begin{array}{l}\text { N90E } \\
\text { SOOW }\end{array}$ & $\begin{array}{l}0.211 \\
0.170\end{array}$ & $\begin{array}{l}\mathrm{Y} \\
\mathrm{X}\end{array}$ \\
\hline $\begin{array}{l}\text { San Fernando, } \\
\text { California }\end{array}$ & $02 / 09 / 71$ & 6.6 & $\begin{array}{l}\text { Griffith Park Observatory, } \\
\text { LA }\end{array}$ & Rock & 31 & $\begin{array}{l}\text { Soow } \\
\text { S90W }\end{array}$ & $\begin{array}{l}0.180 \\
0.171 \\
\end{array}$ & $\begin{array}{l}\mathrm{Y} \\
\mathrm{X} \\
\end{array}$ \\
\hline $\begin{array}{l}\text { San Fernando, } \\
\text { California }\end{array}$ & $02 / 09 / 71$ & 6.6 & 234 Figueroa St., LA & $\begin{array}{l}\text { Stiff } \\
\text { Soil }\end{array}$ & 41 & $\begin{array}{l}\text { N37E } \\
\text { S53E }\end{array}$ & $\begin{array}{l}0.199 \\
0.192\end{array}$ & $\begin{array}{l}\mathrm{Y} \\
\mathrm{X}\end{array}$ \\
\hline $\begin{array}{l}\text { Near S. Coast of } \\
\text { Honshu, Japan }\end{array}$ & $08 / 02 / 71$ & 7.0 & Kushiro Central Wharf & $\begin{array}{l}\text { Stiff } \\
\text { Soil }\end{array}$ & 196 & $\begin{array}{l}\text { N90E } \\
\text { No0E }\end{array}$ & $\begin{array}{l}0.078 \\
0.091\end{array}$ & $\begin{array}{l}\mathrm{X} \\
\mathrm{Y}\end{array}$ \\
\hline $\begin{array}{l}\text { Near E. Coast of } \\
\text { Honshu, Japan }\end{array}$ & $11 / 16 / 74$ & 6.1 & Kashima Harbor Works & $\begin{array}{l}\text { Stiff } \\
\text { Soil }\end{array}$ & 38 & $\begin{array}{l}\text { NOOE } \\
\text { N90E }\end{array}$ & $\begin{array}{l}0.070 \\
0.093\end{array}$ & $\begin{array}{l}\mathrm{X} \\
\mathrm{Y}\end{array}$ \\
\hline $\begin{array}{l}\begin{array}{l}\text { Monte Negro, } \\
\text { Yugoslavia }\end{array} \\
\end{array}$ & $04 / 15 / 79$ & 7.0 & Albatros Hotel, Ulcinj & Rock & 17 & $\begin{array}{l}\text { NooE } \\
\text { N90W }\end{array}$ & $\begin{array}{l}0.171 \\
0.222 \\
\end{array}$ & $\begin{array}{l}X \\
Y\end{array}$ \\
\hline $\begin{array}{l}\text { Michoacan, } \\
\text { Mexico }\end{array}$ & $09 / 19 / 85$ & 8.1 & El Suchil, Guerrero Array & Rock & 230 & $\begin{array}{l}\text { SO0E } \\
\text { N90W }\end{array}$ & $\begin{array}{l}0.105 \\
0.083\end{array}$ & $\begin{array}{l}\mathrm{Y} \\
\mathrm{X}\end{array}$ \\
\hline $\begin{array}{l}\text { Michoacan, } \\
\text { Mexcio }\end{array}$ & $09 / 19 / 85$ & 8.1 & La Villita, Guerrero Array & Rock & 44 & $\begin{array}{l}\text { N90E } \\
\text { NOOE }\end{array}$ & $\begin{array}{l}0.123 \\
0.123\end{array}$ & $\begin{array}{l}\mathrm{Y} \\
\mathrm{X}\end{array}$ \\
\hline
\end{tabular}


balanced system, forming quantities referred to as displacement and ductility ratio. The mean of the displacement ratios obtained using the ensemble of ten records is denoted as $\left(r_{v}\right)_{i}$, where $i$ indicates the element number. Similarly, the mean ductility ratio of element $i$ is denoted as $\left(\mathrm{r}_{\mu}\right)_{\mathrm{i}}$.

For element 3 which is located at the flexible edge, the mean displacement ratios $\left(r_{v}\right)_{3}$ always exceed unity, indicating that there is additional displacement at the flexible edge. Since there is strength increase on element 3 as required by the code provision to compensate the increase in displacement, the resulting mean ductility ratio $\left(\mathrm{r}_{\mu}\right)_{3}$ is less than unity as shown in Figure 6. Therefore, one can expect no additional ductility demand at the flexible edge element due to torsion if the torsional provision is applied.

The displacement ratio $\left(r_{v}\right)_{1}$ for element 1 (stiff edge element) is shown in Figure 7. Each graph corresponds to a particular value of $\lambda$. For a given $\lambda$, the displacement ratio decreases as the torsional stiffness of the system increases. The displacement ratio is larger than unity when $\rho_{\mathrm{k}}$ is less than 0.4. In other words, systems that are torsionally flexible $\left(\rho_{k}<0.4\right)$ would experience larger displacement at the stiff edge than the reference system.

The ductility ratio of any element is related to its displacement ratio as shown below.

$$
r_{\mu}=\frac{\mu}{\mu^{0}}=\frac{\left(v / v_{y}\right)}{\left(v^{0} / v_{y}^{0}\right)}=\frac{\left(v / v^{0}\right)}{\left(v_{y} / v_{y}^{9}\right)}
$$

where $v_{y}$ denotes the yield displacement and superscript 0 denotes quantities associated with the reference system. Since the element stiffness of the reference system is the same as the torsionally unbalanced system, $\mathrm{v}_{\mathrm{y}} / \mathrm{v}^{0},=\mathrm{f} / \mathrm{f}^{0}$. Equation 10 can be rewritten as

$$
\mathrm{r}_{\mu}=\frac{\mathrm{r}_{\mathrm{v}}}{\Gamma}
$$

Since the element ductility ratio $\left(r_{\mu}\right)$ is equal to the element displacement ratio $\left(\Gamma_{v}\right)$ divided by the element strength ratio $\Gamma$, the ductility ratio curves shown in Figure 8 can be seen as the displacement ratio curves shown in Figure 7, normalized by the respective strength ratio curves shown in Figure $3 b$. For a given $\lambda$ configuration, there are peaks in the ductility ratio curves, showing that there can be significant additional ductility demands on the stiff edge element. One can trace the sources which lead to these peaks. For the case of small eccentricity $(\mathrm{e}=0.1)$, the peak is located around $\rho_{\mathrm{k}}=0.23$. There is no reduction of design strength of element 1 in this case. However, the displacement ratio exceeds unity because the system is torsionally flexible. As a result, the ductility ratio peak associated with small eccentricity is caused by the system being too flexible. The ductility ratio peaks associated with large eccentricities $(e=0.2,0.3$ and 0.4$)$ are at locations where $\rho_{k}=\rho_{k, c r}$. They are essentially a reflection of the strength ratio troughs in Figure $3 \mathrm{~b}$. In other words, these peaks are the consequence of excessively low design strength of the element rather than additional displacement at the stiff edge due to torsional responses.

\section{MINIMUM DESIGN TORSIONAL STIFFNESS}

To avoid the large ductility ratio peaks in element 1 , one should not have torsional stiffness of the system in the neighbourhood of $\rho_{k}$,cr. This can be achieved by providing guidelines in the form of minimum design torsional stiffness, $\rho_{k, \min }$ in the design process. The large ductility peaks associated with systems having large eccentricity can be avoided by specifying the minimum acceptable value of $\rho_{k}$ as function of $e$. If the system remains in the elastic range, $\mathrm{e}$ is proportional to the induced torsional moment while $\rho_{\mathrm{k} 2}$ is proportional to the torsional restoring moment. In the inelastic range, such interpretation is not strictly true, but should also serve as a first order approximation to specify the minimum acceptable torsional stiffness. It is proposed therefore that this lower bound of torsional stiffness takes the form

$$
\rho_{\mathrm{k}, \min }=\sqrt{\mathrm{e}}
$$

Using equation $12, \rho_{\mathrm{k}, \min }$ for systems having $\mathrm{e}=0.1,0.2,0.3$ and 0.4 is $0.32,0.45,0.55$ and 0.63 respectively. Referring to Figure 8 , it can be seen that systems having these eccentricities but having $\rho_{\mathrm{k}}$ larger than the corresponding $\rho_{\mathrm{k}, \min }$ values will have ductility ratios of one or less. In other words, the restriction $\rho_{k} \geq \sqrt{\text { e would ensure little or no }}$ additional ductility demand on element 1 for these systems.

The implication of the minimum torsional stiffness requirements in design is given in Figure 9. Shown in the figure is the ratio of the stiffness of element 1 to total stiffness as a function of $\rho_{\mathrm{k}}$. For a centrally located CR configuration, the stiffness of elements 1 and 3 are equal $\left(k_{\mathrm{y} 1}=\mathrm{k}_{\mathrm{y} 3}\right)$. Therefore, the maximum value of $\mathrm{k}_{\mathrm{y} 1} / \mathrm{k}_{\mathrm{y}}$ is 0.5 . For structural configuration where the contribution to torsional stiffness comes from Y direction only $(\lambda=0)$, the maximum attainable $\rho_{\mathrm{k}}$ is 0.5 . The minimum torsional stiffness requirement suggests that for such a configuration, the stiffness distribution should be mainly along the edges of the building if the eccentricity e is larger than 0.2. Most structural framing will have contributions to the total torsional stiffness coming from elements spanning in two directions. Consider the case of a building having resisting elements in two orthogonal directions and they contribute equally to the overall stiffness of the building $(\lambda=0.5)$. For a fairly large eccentricity $e=0.25$, the minimum $\rho_{k}$ value $=0.5$. Figure 9 shows that $\rho_{k} \geq \sqrt{e}$ is satisfied if the edge elements each contribute $25 \%$ to the total $\mathrm{Y}$ direction stiffness. Therefore, it is believed that the minimum torsional stiffness requirement will be satisfied in most buildings with reasonable framing.

\section{EVALUATION OF $\rho_{k}$ and e}

To apply the minimum torsional stiffness criteria equation 12 in practice there is a need for a simple procedure to establish the value of $\rho_{k}$ and eccentricity e of the structure without involving the knowledge of CR locations. Two loading cases are involved when the torsional provision is applied. The first loading case involves the application of lateral loads at $+0.1 b$ distance from $\mathrm{CM}$ while the second loading case involves the application of loads at $-0.1 \mathrm{~b}$ distance from $\mathrm{CM}$ at each floor. The displacement at the flexible edge $v_{3}$ and at the stiff edge $v_{1}$ in each of these load cases are given by: 
NZS Code, Element 3
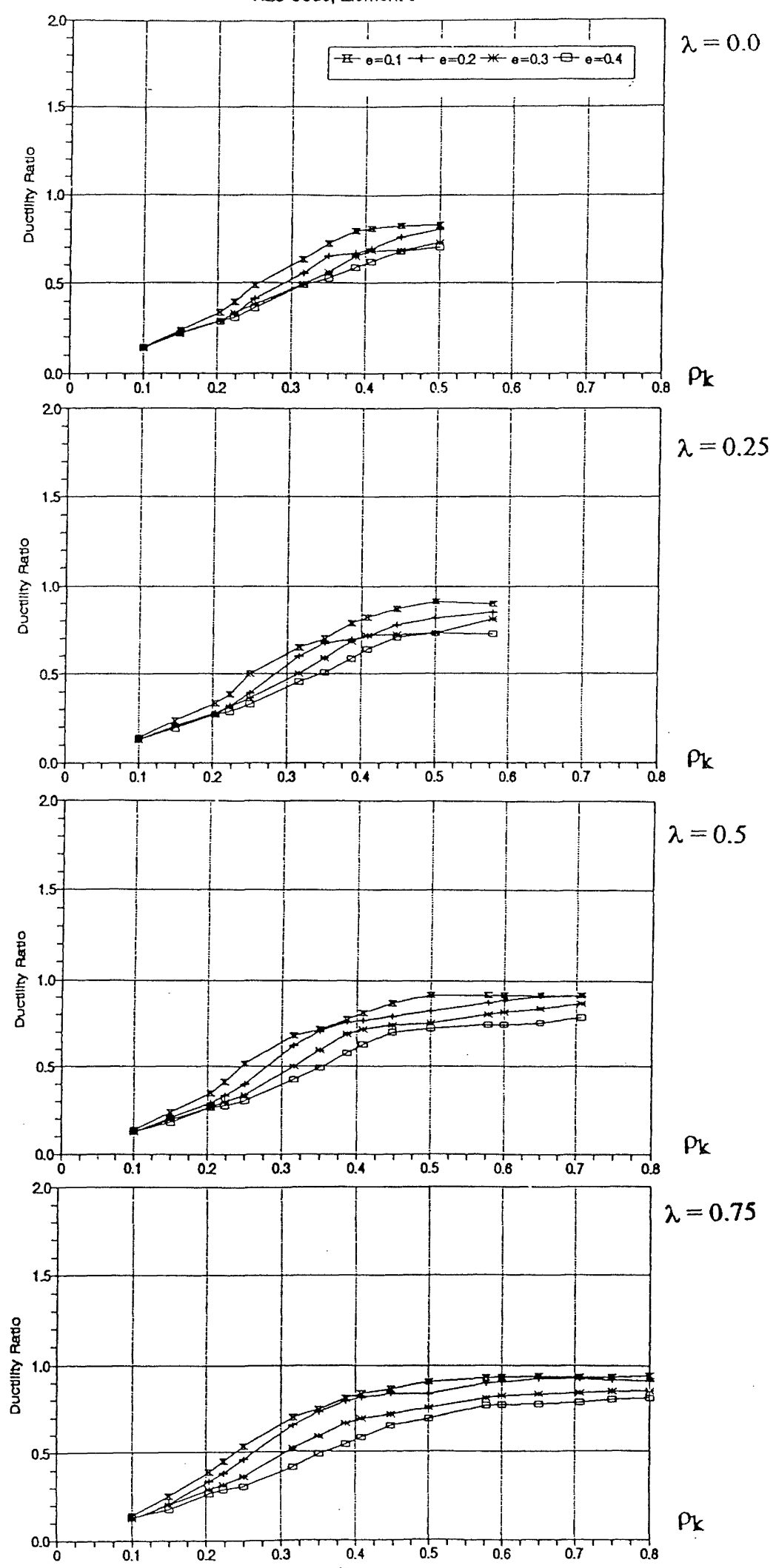

Figure $6 \quad$ Mean ductility ratios for element 3. 

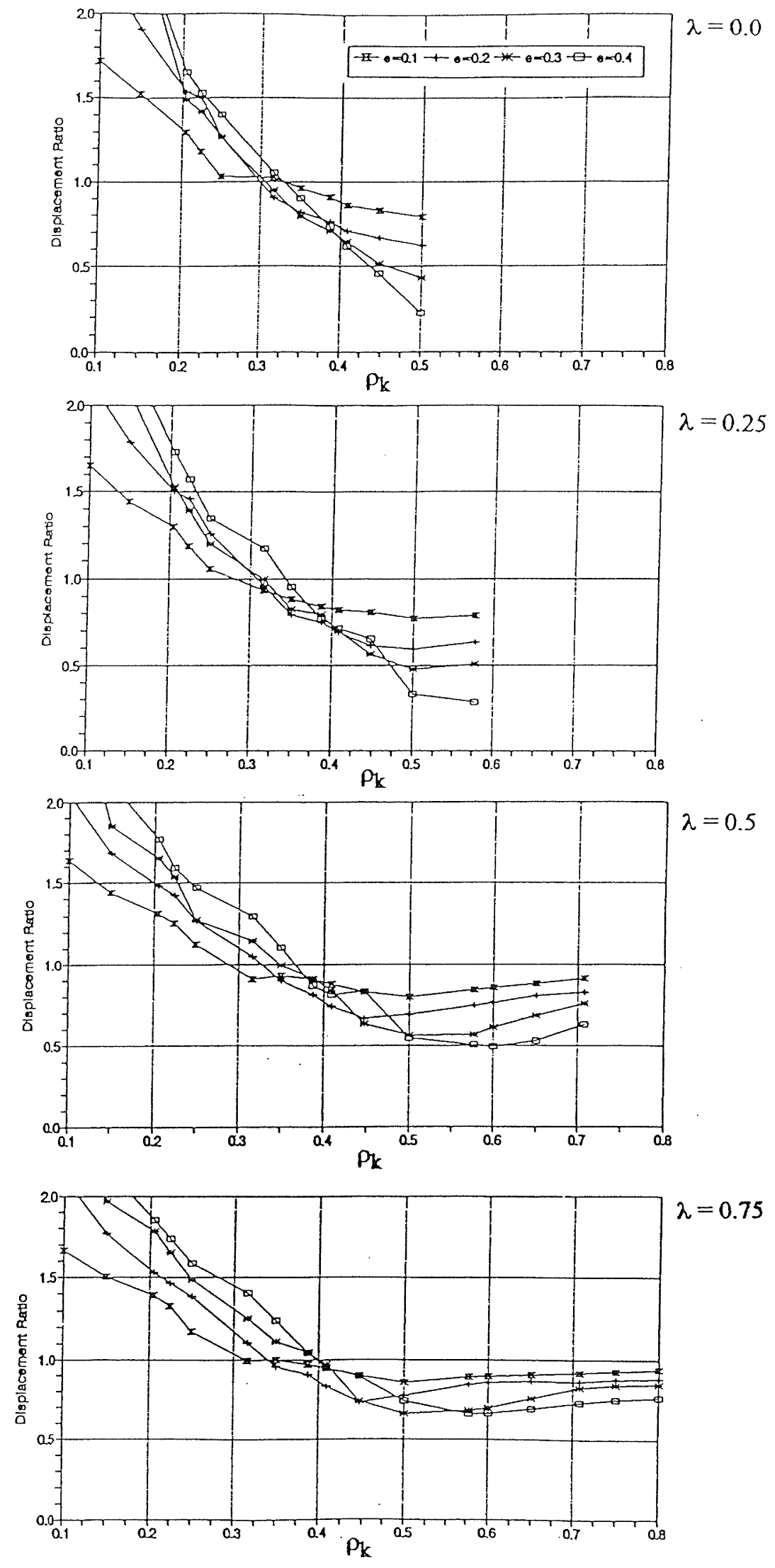

Figure $7 \quad$ Mean displacement ratios for element 1. 



Figure $8 \quad$ Mean ductility ratios for element 1. 


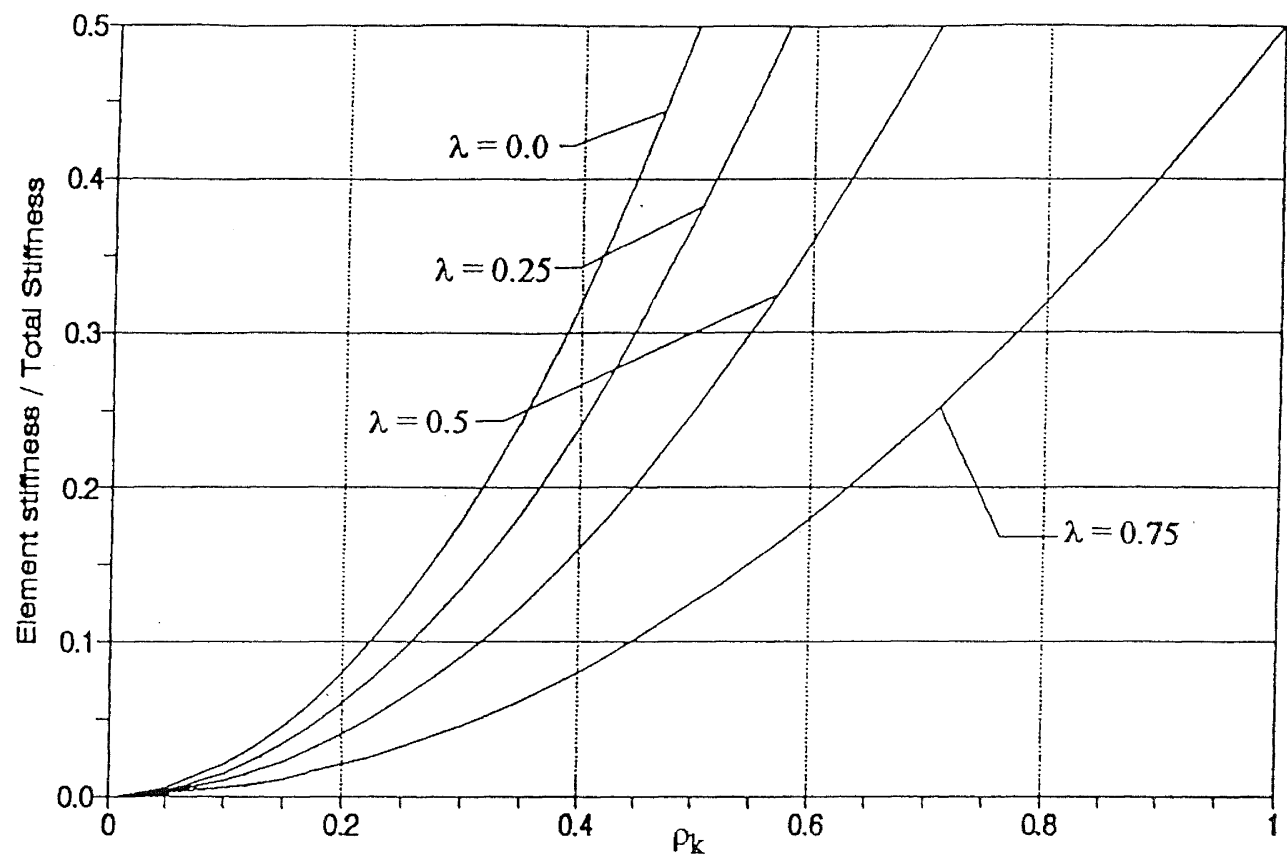

Figure 9 Element 1 stiffness ratio for centrally located CR configuration.

$$
\left(v_{3}\right)^{+,-}=v^{0}\left[1+\frac{(e \pm 0.1) x_{3}}{\rho_{k}^{2}}\right]
$$

where the superscript + and - denote the load cases having the loads applied at $+0.1 \mathrm{~b}$ or $-0.1 \mathrm{~b}$ from $\mathrm{CM}$, respectively

$$
\left(\mathrm{v}_{1}\right)^{+,-}=\mathrm{V}_{0}\left[1-\frac{\left(\mathrm{e} \pm 0.1\left|\mathrm{x}_{1}\right|\right)}{\rho_{\mathrm{k}}^{2}}\right]
$$

$v^{0}$ is the lateral displacement when the loads are applied at $\mathrm{CR}$ and is equal to $\mathrm{F} / \mathrm{k}_{\mathrm{y}}$. Using equations 13 and 14 , the eccentricity $\mathrm{e}$ and torsional stiffness parameter $\rho_{\mathrm{k}}$ can be expressed as

$$
\begin{gathered}
\rho_{\mathrm{k}}^{2}=\frac{0.2\left(\mathrm{v}_{3}^{+} \mathrm{v}_{1}^{-}-\mathrm{v}_{3}^{-} \mathrm{v}_{1}^{+}\right)}{\mathrm{b}^{2}\left(\theta^{+}-\theta^{-}\right)} \\
\mathrm{e}=\frac{0.1\left(\theta^{+}+\theta^{-}\right)}{\left(\theta^{+}-\theta^{-}\right)}
\end{gathered}
$$

where $\theta^{+} \equiv\left(\mathrm{v}_{3}^{+}-\mathrm{v}_{1}^{+}\right) / \mathrm{b}, \quad \theta \equiv\left(\mathrm{v}_{3}^{-}-\mathrm{v}_{1}{ }^{-}\right) / \mathrm{b}$. They represent the rotations of the deck when the system is subjected to loadings at locations $-0.1 \mathrm{~b}$ from CM. Since $\mathrm{v}_{3}{ }^{+}$, $\mathrm{v}_{1}{ }^{+}, \mathrm{v}_{3}{ }^{-}$and $\mathrm{v}_{1}{ }^{-}$can be obtained readily from the outputs of computer analysis, equations 15 and 16 provide a convenient way to compute $\rho_{k}$ and $e$ in practice.

\section{MODIFICATION OF PROVISIONS FOR TORSIONALLY FLEXIBLE STRUCTURES}

If a torsionally unbalanced system having a torsional stiffness less than that specified in equation 12 , the code provision in the 1984 edition of NZS 4203 allows excessive reduction of strength in element 1 . To avoid such consequence, the strength factor $\left(\Gamma_{1}\right)_{\mathrm{b}}$ as given in equation $7 \mathrm{~b}$ should be modified. The modification takes the form

$$
\left(\Gamma_{1}\right)_{b}=1-\frac{\left|x_{1}\right|}{\rho_{k}^{2}}\left(\rho_{k}^{2}-0.1\right)
$$

applicable when $\rho_{k 2}<$ e. Equation 17 is the result of replacing e by $\rho_{\mathrm{k} 2}$ in equation $7 \mathrm{~b}$. This replacement has the effect of restricting the reduction of strength of element 1 .

In the design of element 1 , one should use either $\left|\left(\Gamma_{1}\right)_{a}\right|$ as given in equation $7 \mathrm{a}$ or $\left(\Gamma_{1}\right)_{\mathrm{b}}$ as given in equation 17 for torsionally flexible systems. The strength ratios of element 1 for different eccentricity e with the incorporation of equation 17 are shown in Figure 10. The effect of the proposed modification on the strength of the stiff edge element can be judged by comparing this figure to Figure $3 \mathrm{~b}$.

The mean ductility ratio $\left(r_{\mu}\right)$ for the stiff edge element for a system design based on the proposed modification is shown in Figure 11. By eliminating the strength ratio troughs, one also eliminates the mean ductility ratio peaks and the resulting mean ductility ratios are all in the neighbourhood of unity or less, indicating that there is essentially no additional ductility demand on element 1 for the whole range of $\rho_{k}$ considered.

\section{IMPLICATION OF EDGE DISPLACEMENT CRITERION}

To use the design eccentricity expressions (5a and $b$ ) in conjunction with the equivalent static method, the current edition of the Code requires the structure to satisfy the horizontal regularity requirements (NZS 4203:1992). One of the requirements states that the ratio of the horizontal displacements at the ends of an axis transverse to the direction of the applied lateral forces shall be in the range $3 / 7$ to $7 / 3$. This requirement defines what is the minimum acceptable torsional stiffness according to the code, and therefore is an indirect specification of $\rho_{k, \text { min }}$. The implication and significance of this requirement is discussed in this section. 


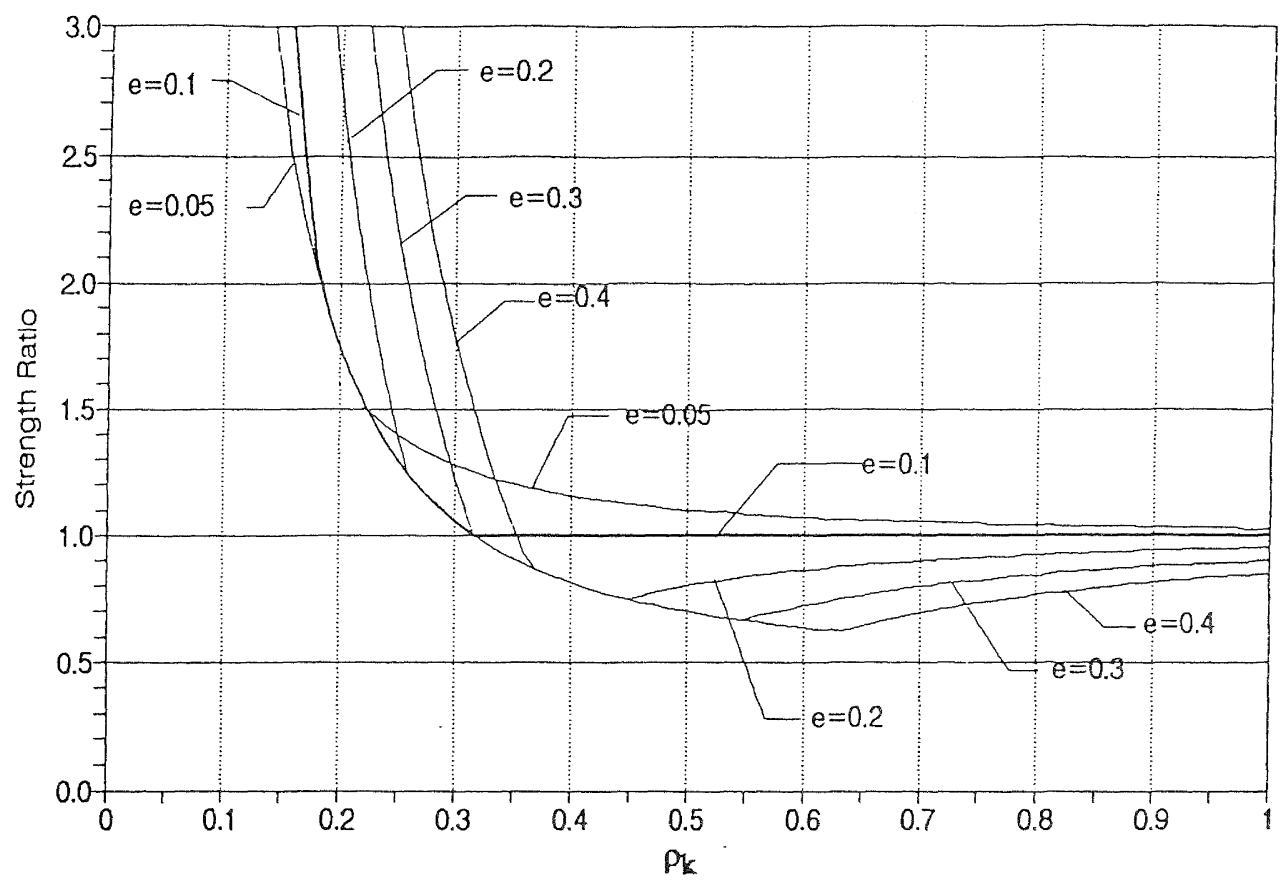

Figure 10 Strength ratio for stiff edge element 1 after modification incorporated.

To cover all structural plan configurations, two situations need to be considered. The first situation corresponds to configurations where $\mathrm{CM}$ is to the right of $\mathrm{CR}$ (i.e. $\mathrm{e} \geq 0$ ). When one applies the equivalent static force at a distance $0.1 \mathrm{~b}$ from $\mathrm{CM}$, the structure is subjected to two possible sets of loadings, load cases 1 and 2 when the eccentricity is larger than $0.1 \mathrm{~b}$ or load cases 1 and 3 when eccentricity is less than $0.1 \mathrm{~b}$, as shown in Figure 12a. When subjected to load case 1, the edge displacements can be written as

$$
\begin{aligned}
& \mathrm{v}_{1}=\mathrm{v}_{0}\left(1-\frac{\mathrm{e}+0.1}{\rho_{\mathrm{k}}^{2}}\left|\mathrm{x}_{1}\right|\right) \\
& \mathrm{v}_{3}=\mathrm{v}_{0}\left(1+\frac{\mathrm{e}+0.1}{\rho_{\mathrm{k}}^{2}} \mathrm{x}_{3}\right)
\end{aligned}
$$

The Code requirement of $\mathrm{v}_{1} / \mathrm{v}_{3} \geq 3 / 7$ is equivalent to the condition

$$
\rho_{\mathrm{k}}^{2}=(\mathrm{e}+0.1)(1.25-\eta)
$$

Similarly, the Code requirement on edge displacements for load cases 2 and 3 is given by conditions:

$$
\begin{aligned}
& \text { Loadcase2: } \\
& (\mathrm{e} \geq 0.1) \quad \rho_{\mathrm{k}}^{2} \geq(\mathrm{e}-0.1)(1.25-\eta) \\
& \text { Loadcase3: } \\
& \quad(\mathrm{e}<1) \quad \rho_{\mathrm{k}}^{2} \geq(0.1-\mathrm{e})(1.25+\eta)
\end{aligned}
$$

It can be seen from equations 19 that the Code requirement on $\rho_{k, \min }$ is a function of eccentricity e, and the location of $\mathrm{CR}$ in relation to the geometric centre $(\eta)$. equation 19a always gives a larger $\rho_{\mathrm{k} \text { min }}$ than that given in equation $19 \mathrm{~b}$. It also leads to a larger $\rho_{k, \text { min }}$ than given in equation $19 \mathrm{c}$ except for situations of very small e. The minimum $\varrho_{k}$ given by equations 19 is plotted as a function of e for three values of $\eta$ as shown in Figure 13a. Shown in the same figure is the minimum $\rho_{k}$ suggested in equation 12 . It can be seen that the $\rho_{k, \min }$ calculated on the code requirement is larger than the $\rho_{\mathrm{k} \text { min }}$ suggested by equation 12 . Since there is little or no additional ductility demand on the stiff edge element using the $\rho_{k \text { min }}$ defined by equation 12 , one can expect there will be no additional ductility demand on the stiff edge element if the structure will have a torsional stiffness that satisfies the horizontal regularity requirement of NZS 4203:1992.

The second situation corresponds to configurations where $\mathrm{CM}$ is to the left of $\mathrm{CR}$ (i.e. e $<0$ ). The three possible load cases encountered in this situation are shown in Figure $12 \mathrm{~b}$. The Code requirement is equivalent to:

Load case $1: \quad \rho_{\mathrm{k}}^{2} \geq(|\mathrm{e}|+0.1)(1.25+\eta)$

Load case 2:

$$
\left.(|\mathrm{e}|>0.1) \quad \rho_{\mathrm{k}}^{2} \geq(|\mathrm{e}|)-0.1\right)(1.25+\eta)
$$

Load case 3:

$$
(|\mathrm{e}|<0.1) \quad \rho_{\mathrm{k}}^{2} \geq(0.1-|\mathrm{e}|)(1.25+\eta)
$$

The $\rho_{k, \min }$ as required by equation $20 \mathrm{a}$ governs in this situation and this $\rho_{\mathrm{k} \text { min }}$ is plotted as a function of $\mathrm{e}$ and shown in Figure 13b. Again, the $\rho_{k, \min }$ that will satisfy the code is larger than that given by equation 12 . 

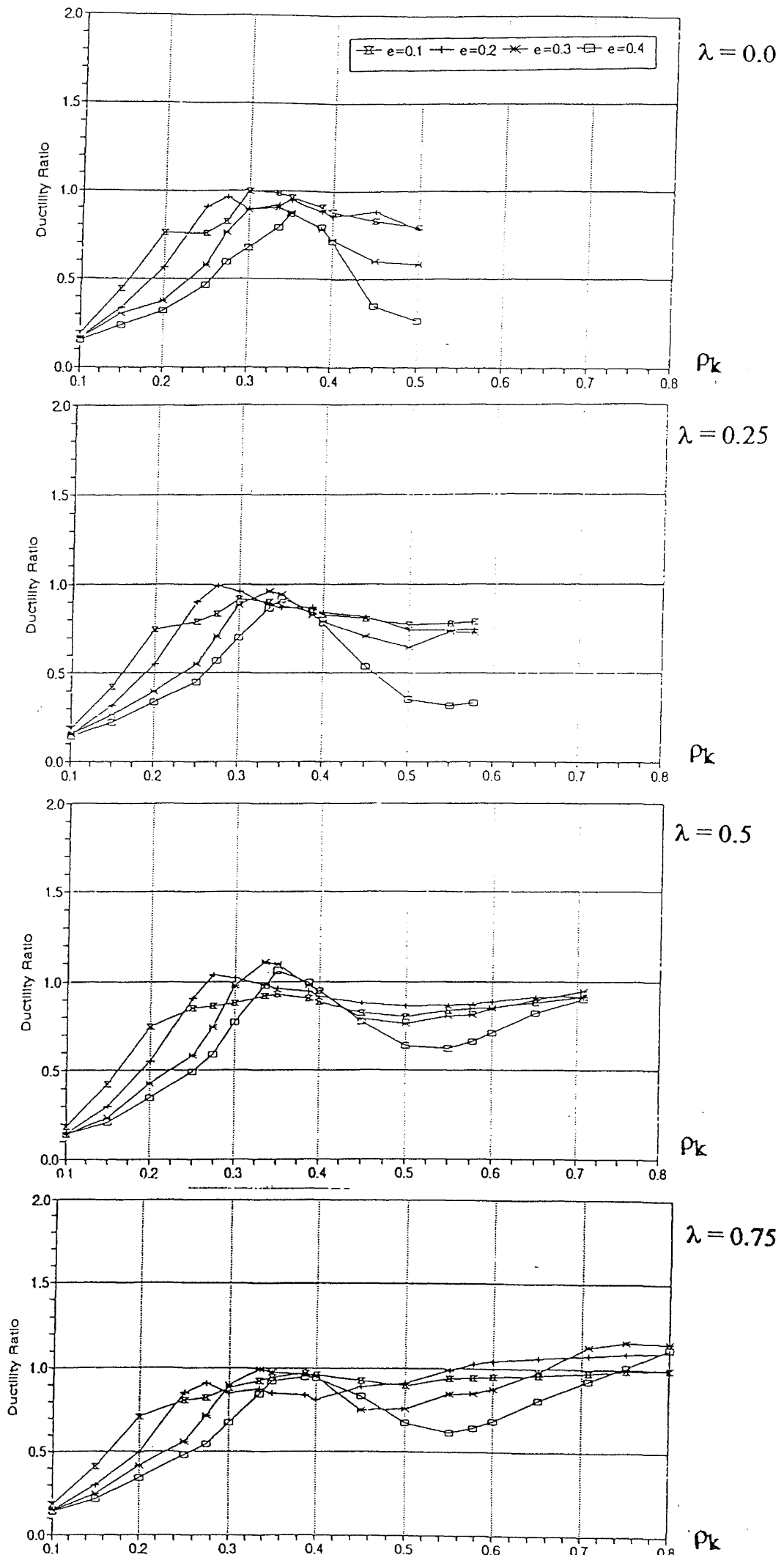

Figure 11 Mean ductility ratio for element 1 after modification incorporated. 


\section{DISCUSSION AND CONCLUSIONS}

The torsional provision of the New Zealand code was evaluated, based on a study of the inelastic seismic responses of a single mass torsionally unbalanced model. The study focuses on the ductility demands on the lateral load resisting elements in the model. The adequacy of the torsional provision is judged on its ability to maintain the ductility demands on the edge elements of the torsionally unbalanced system at a level no higher than those of a torsionally balanced reference system having the same stiffness distribution but with the mass centre coinciding with the rigidity centre. The provision in the 1984 edition of NZS 4203 is able to ensure the ductility demand of the elements at the flexible edge to be equal to or less than that of the reference system. The ductility demand of the elements at the stiff edge may exceed substantially the ductility demand of the corresponding elements of the reference system because the current code allows excessive reduction of element strength under certain circumstances.

A minimum torsional stiffness criterion is suggested in this paper and it is shown that for systems with torsional stiffness that exceeds this minimum, there will be no additional ductility demand on the stiff edge elements. The current (1992) edition of the code imposed a new criterion relating to the edge displacement ratio to ensure a structure will have adequate torsional stiffness. Structures that satisfy the code edge displacement ratio requirement will have a torsional stiffness that exceeds the suggested minimum. Therefore, the torsional provision in the current New Zealand code can limit the ductility demands on the elements at both edges of a torsionally unbalanced structure to be no higher than those in a torsionally balanced structure having the same stiffness distribution.

\section{ACKNOWLEDGEMENT}

The writers wish to thank the Natural Sciences and Engineering Research Council of Canada (NSERC) for supporting the work presented herein. They also acknowledge the contributions from Tom Paulay of Canterbury University who pointed out to them the importance of torsional stiffness on seismic torsional responses.

\section{REFERENCES}

1. Esteva, L. (1987), "Earthquake engineering research and practice in Mexico after the 1985 earthquake", Bull. N.Z. Nat. Soc. Earthquake Eng., Vol. 20, pp. 159-200.

2. Chopra, A.K. and R.K. Goel (1991), "Evaluation of torsional provision in seismic codes", J. Structural Engineering, Vol. 117, No. 12, pp. 3762-3782.

3. Tso, W.K. and T.J. Zhu (1992), "Design of torsionally unbalanced structural systems based on code provisions, Part I: ductility demand", J. Earthquake Engineering and Structural Dynamics., Vol. 21, pp. 609-628.

4. Zhu, T.J. and W.K. Tso (1992), "Design of torsionally unbalanced structural systems based on code provisions, Part II: strength distribution", J. Earthquake Engineering and Structural Dynamics., Vol. 21, pp. 629-644.

5. Rutenberg, A., M. Eisenberger and G. Sholet (1992), "Inelastic seismic response of code designed single storey asymmetry structures", J. Engineering Structural, Vol. 14, No. 2, pp.91-102.

6. Rutenberg, A., A. Benbenishti and O.A. Pekau (1992), "Nonlinear seismic behaviour of code designed eccentric systems", Proc. 10th World Conf. Earthquake Eng., Madrid, Spain, Vol. 10, pp. 5751-5756.

7. New Zealand Standard: NZS4203, (1984), "Code of Practice for General Structural Design and Design Loadings for Buildings", Standards Association of New Zealand, Wellington, New Zealand.

8. New Zealand Standard: NZS4203, (1992), "Code of Practice for General Structural Design and Design Loadings for Buildings", Clause 4.4.1, Standards Association of New Zealand, Wellington, New Zealand. 